\title{
OS 200 ANOS DE MARX E O DESTINO DE SUA OBRA
}

\author{
THE 200 YEARS OF MARX AND THE DESTINY OF HIS WORK
}

Ester Vaisman ${ }^{*}$

\section{RESUMO}

$\mathrm{O}$ artigo pretende abordar de modo breve algumas características da recepção da obra de Marx tanto ao longo do século XX quanto na atualidade, indicando simultaneamente as possíveis causas das ocorrências sucessivas ao longo do tempo de distorções e malentendidos. Ao final do texto apontam-se as razões para o necessário balanço crítico acerca dos problemas assim identificados, os quais acarretam danos severos no plano teórico e no plano prático.

PALAVRAS-CHAVE: Marx. Marxismo. Marxologia. Stalinismo. Gnosiologia. Ontologia.

\section{ABSTRACT}

The article intends to address some characteristics of the reception of the Marx' work throughout the twentieth century and nowadays. It also intend to indicate the possible causes of these problems that generate distortions and misunderstandings. At the end of the text it points out the reasons for the necessary critical assessment of the problems thus identified, problems that bring on severe damages in theoretical and practical terms.

KEY WORDS: Marx. Marxism. Marxology. Stalinism. Gnosiology. Ontology.

\section{INTRODUÇÃO}

Estou convencida - e o itinerário de pesquisa criado na UFMG, por J. Chasin há pouco mais de trinta anos tem demonstrado - que décadas são necessárias para recuperar devidamente o pensamento de Marx. Não afirmo que fomos exitosos nessa empreitada: a modéstia criada e nutrida ao longo de mais de quarenta anos de pesquisa e docência, em que obstáculos de diferentes aspectos se colocaram no caminho, me impedem de cair em postulações arrogantes ou autocomplacentes. Mesmo porque G. Lukács, o filósofo que buscou intensamente em sua obra de maturidade o "retorno a Marx", se vivo, muito provavelmente não afirmaria que seu empenho tivesse atingido a meta almejada. Isso não significa, no entanto, que tal empreitada seja absolutamente inviável, ou que o objetivo de identificar o que Marx efetivamente pensou e escreveu seja algo como um ideal regulador: meta posta no horizonte a orientar nossa conduta, mas sabidamente inatingível. Definitivamente não é isso.

\footnotetext{
* Doutora. Professora titular do Departamento de Filosofia da UFMG. E-mail: evaisman@ fafich.ufmg.br.
} 
Trata-se muito mais de reconhecer, de imediato, a dificuldade da tarefa, identificando o modo como a herança marxiana foi e tem sido recebida.

\section{O DESTINO TRÁGICO DO PENSAMENTO DE MARX E A REDESCOBERTA DE SEU PENSAMENTO}

Antes de tudo é forçoso reconhecer que o pensamento de Marx conheceu um destino teórico trágico. ${ }^{1}$ Essa constatação perturbadora, necessário ponto de partida para qualquer empenho em se debruçar sobre a obra do autor, deve ser reconhecida como uma das múltiplas vicissitudes contraditórias do século passado, mas que insiste em permanecer até nossos dias, embora com aspectos distintos.

O itinerário que marca e demarca tal destino nos leva a afirmar que quanto mais foi invocado, tanto menos era efetivamente conhecido. E o desconhecimento maior e mais comprometedor se deu precisamente no concernente ao seu universo filosófico, mas com amplas e graves repercussões para todas as áreas, tendo em vista o caráter decisivo daquele tipo de reflexão para a devida apreensão do tecido teórico da obra marxiana. Em realidade, são muito recentes os esforços de resgate nesse âmbito; de fato só principiaram a ocorrer por efeito dos dilemas críticos em que vieram a desembocar e ruir os "herdeiros" práticos e teóricos que dominaram o século XX, mas que insistem, apesar da debacle, em dominar a cena nos dias que correm, apesar da sua caducidade comprovada teórica e praticamente.

Esforços recentes e, infelizmente, limitados se sintetizam no propósito de redescobrir Marx. Trata-se de caminho trabalhoso e multifacético, nem sempre na "crista da onda", mas o único apropriado nas condições existentes para apreensão do pensamento marxiano, submerso por décadas sob a aludida nuvem de desconhecimento e deformação que obviamente não beneficia a inteligência nem a existência global em nossos tempos.

Tempos esses vividos em que as manifestações mais clamorosas são determinadas figurações da subjetividade - a razão manipuladora e a desrazão - cujo enraizamento objetivo se encontra, "no prolongamento da utilidade histórica do capital" (CHASIN, 1989, p. 3) e de sua forma de sociabilidade, "sob cuja lógica e regência move-se o universo humano-societário

\footnotetext{
${ }^{1}$ Reflexões dessa natureza foram desenvolvidas em parte já em minha tese de doutorado defendida em 1996 (FaE-UFMG), cujo título é A determinação marxiana da ideologia. Passados 22 anos, mantenho a avaliação realizada e considero que nesse intervalo de tempo a situação só fez piorar por motivos cujo sentido básico indico mais à frente.
} 
contemporâneo", com as mais devastadoras consequências, tanto para o indivíduo quanto para a sociedade, que se vergam debaixo das piores renúncias.

Na atualidade, a interrogação de rigor - sobre a irredutível natureza social humana e a historicidade intrínseca à sociabilidade, conquistas da obra de Marx - constitui a plataforma geral que pode vir a dinamizar o clareamento do ser e saber da cotidianeidade, como o entendimento e a prática da atividade científica. Nesse resgate da subjetividade ativa, racionalmente potencializada, o oponente que ela tem de enfrentar são as mil faces de sua negação, que se reiteram impiedosamente em todos os espaços tanto individuais quanto sociais, desde a renúncia cética até a impertinência da desrazão.

É evidente que não é o caso aqui de tematizar em termos concretos e amplos o conjunto dessa problemática, tão vital em nosso tempo, mas o de afirmar o destino trágico do pensamento marxiano e indicar brevemente suas razões e consequências, alertando para o que está em causa. Em outras palavras, a denúncia acerca do destino do legado de Marx não é uma questão meramente acadêmica, como os desavisados ou deletérios poderiam conjecturar, mas se trata de problema crucial a ser compreendido e superado, tendo em vista a sua íntima conexão com os desafios de nosso tempo, sejam eles práticos ou teóricos.

Colocando o argumento de outra maneira: está-se num determinado lugar e numa determinada época, e tais condições alteram o modo por meio do qual algo possa ser apreendido. A obra de Marx tem diante de si uma barragem, uma série de obstáculos de várias ordens e níveis de complexidade que devem ser enfrentados e superados para que se possa chegar até aquilo que ele realmente pensou e escreveu. Marx morreu em 1883, e nesse intervalo de tempo até hoje ocorreram diversas situações, tanto no plano histórico concreto quanto no plano das ideias, todas no sentido de tornar mais penosa a compreensão e a assimilação do pensador alemão. Além disso, deve-se reconhecer também que na atualidade tornou-se ato de coragem e ousadia sustentar a ideia de que Marx seja ainda um pensador a ser redescoberto.

O itinerário trágico que marca e demarca a trajetória do pensamento de Marx - aqui meramente aludido, pois não se tem a pretensão nesse espaço de configurá-lo concretamente em suas marchas e contramarchas - tem início pouco depois de sua morte, pois

já se impunha e prevalecia a paródia da II Internacional; e dadas as condições e urgências políticas, em que se desenvolveu a tentativa de recuperação de sua obra pela socialdemocracia russa [...] esse resgate ficou sempre confinado a limites muito estreitos, [...] vindo a desaparecer por completo com a caricatura teórica da 'era stalinista', que se irradiou pelo mundo e pela qual, ainda hoje, salvo em restritos 
bolsões de especialistas, o ideário marxiano é em geral tomado e combatido. (CHASIN, 1989, p. 28).

Fenômeno não muito diferente ocorre também com os assim denominados "inimigos sérios" de Marx, que sem nenhuma inibição e rigor preferem construir "o monstro por conta própria do que lidar com sua legítima figura intelectual” (CHASIN, 1989, p. 29).

Como consequência, o valor intrínseco do pensamento de Marx - com raríssimas exceções: Korsch, Gramsci e Lukács, nos anos vinte do século passado, embora tenham passado a ser conhecidos como "clássicos da heresia" e seus esforços não podem ser reconhecidos como resolutivos - dado em parte a alta complexidade do problema que defrontaram -, ficou profundamente obscurecido.

Basta lembrar que Lukács só no decênio posterior infletiu em direção às instaurações filosóficas de Marx, trilhando a partir de então e pelo resto da vida um itinerário de recuperação e desenvolvimento da herança marxiana, que culminou na velhice, cujos resultados, todavia, não exerceram até agora a devida influência. (CHASIN, 1989, p. 29). ${ }^{2}$

O quadro histórico-teórico do marxismo se reduz, todavia, dado o seu largo predomínio, ao marxismo vulgar. Trata-se, sinteticamente, de um indigente esquema de fórmulas:

\begin{abstract}
nascido da adversidade soviética para a transição socialista [...] amálgama do voluntarismo político, entoado pela impotência revolucionária em face das transformações sociais não realizadas e da exacerbação racionalista do cientificismo da II Internacional, que assegura a mecanicidade da sucessão dos modos de produção. O primeiro sustenta e reitera a fidelidade ao objetivo não cumprido, o segundo a validade da rota arbitrária, assumida como sucedâneo. Em suma mera idealidade política para cobertura e reforço do exercício político real, substitutivo da revolução social impossível”. (CHASIN, 1989, p. 29).
\end{abstract}

Em suma, tem-se, como uma espécie de maré montante, o avolumar-se de tendências de interpretação, cuja culminância e cristalização, incluída aí a mediação da II Internacional, num "marxismo" que, sinteticamente, reduz o pensamento de Marx a uma espécie de teoria econômica da infalibilidade do advento de inflexões históricas, para as quais a atividade humana é considerada mero epifenômeno. Evidentemente que os impasses e irrealizações decorrentes da suposta transição socialista no leste e em outras localidades intensificaram

\footnotetext{
${ }^{2}$ É bem verdade que nas últimas décadas publicações de Lukács e sobre ele se avolumaram notadamente no Brasil, mas uma avaliação preliminar sobre seu impacto indica - pelo menos até o momento - que seu pensamento padece de um destino semelhante daquele de Marx: vulgarização deformante, com raras exceções.
} 
ainda mais a obliteração do quadro herdado, transformando, desse modo, o já combalido exercício teórico marxista em mera ideologia (é claro no sentido pejorativo) de sustentação do poder de Estado.

Seja como for, no que concerne aos esforços de renovação da letra marxiana, a partir de meados do século passado, é possível constatar, entretanto, o início de uma reação que mirava reverter o quadro desastroso em que se encontrava o pensamento de Marx, mas de outro, é necessário frisar, foi "movida também por vetores teóricos extramarxistas, que moldaram sua fisionomia" (CHASIN, 1989, p. 29, grifo nosso). Trata-se da polêmica gnosiológica que buscava fundamentar e estabelecer o estatuto científico do discurso marxiano, ou seja,

\begin{abstract}
a movimentação epistemologista em torno da obra marxiana, cujo esgotamento é recente, mas cujo prolongamento atmosférico ainda se vive. Porém, a dada altura de seu curso, a sofisticação dessa inclinação reflexiva foi insuficiente para impedir a contradita de uma nova reação de caráter político que, à unilateralidade deformante do epistemologismo, pretendeu responder com a unilateralidade igualmente deformante do politicismo - identificação da reflexão marxiana como centrada e fundada na política. (CHASIN, 1989, p. 29).
\end{abstract}

Em uma palavra, o destino trágico da herança do pensamento de Marx tem início com o emergir da II Internacional, conhece a total decadência com a vulgata stalinista e seus prolongamentos e se viu reforçado, não obstante evidentes e importantes diferenças "pela especulação epistemologista e politicista, formas de descaracterização e perda da revolução teórica realizada por Marx" (CHASIN, 1989, p. 29). O predomínio dessas duas ordens de interpretação implica, de fato a perda do

centro nervoso do pensamento marxiano, - a problemática, real e idealmente inalienável, da emancipação humana ou do trabalho, na qual e somente pela qual a própria questão da prática radical ou crítico-revolucionária encontra seu télos, identificando na universalidade da trama das atividades sociais seu território próprio e resolutivo, em distinção à finitude da política, meio circunscrito dos atos negativos nos processos reais de transformação. (CHASIN, 1999, p. 11).

Nesse contexto, restou desconhecida a problemática do

ser e destino do homem que abstrata e muitas vezes mesquinhamente atravessa a história recente da filosofia, [e que] não é para Marx meramente que a pobreza de uso, acabou por conferir ao termo humanismo; não é um glacê sobre o oco, mas a questão prático-teórica por excelência, o problema permanente e constante, que não desparece nem pode ser suprimido. (CHASIN, 1989, p. 30). 


\section{O LEGADO DE MARX}

A obra de Marx se encontra formulada no interior de uma longa tradição de vários séculos, e pode ser concebida como o resultado de um longo itinerário do pensamento ocidental e, enquanto tal, sua contribuição específica se constitui como continuidade e descontinuidade simultâneas com determinadas vertentes, tratando-se de um diverso padrão de racionalidade regido por uma ontologia de caráter estatutário. Após a publicação da obra tardia de Lukács $^{3}$ e de um conjunto relativamente expressivo de pesquisas a respeito do tema, há evidências suficientes que os escritos de Marx acompanham e são o resultado, por continuidade e descontinuidade, do mais consistente posicionamento ontológico que atravessa a história da filosofia.

Mas do quê se trata? Com o intuito de responder em termos breves a questão ${ }^{4}$ pode-se dizer que não se trata evidentemente da ontologia tradicional, nem muito menos das tentativas de fundo fenomenológico muito conhecidas na contemporaneidade. Ademais, não consiste em uma teoria filosófica, isto é um campo especializado da filosofia, que se caracterize e se resolva por andamentos autônomos e a priori da razão, na exata medida em que o pensamento de Marx é absolutamente avesso a qualquer procedimento especulativo, a qualquer tipo de espírito de sistema como também incompatível com as querelas da fundamentação tão ao gosto dos estudiosos da filosofia. Trata-se de ontologia de caráter estatutário porque se constitui em uma

ordem do reconhecimento ou reprodução teórica da identidade, natureza e constituição das coisas em si (seres ou entes) por seus complexos categoriais mais gerais e decisivos, independentemente, em qualquer plano, de se tornarem objetos de prática ou reflexão. Nesse sentido, é a teoria do reconhecimento da objetividade histórico-imanente em suas distintas formas e apresentações (natureza e sociedade). É o momento mais abstrato do reconhecimento da identidade das coisas em si, enquanto tal um dos momentos distintos da unidade do saber, do qual participa um segundo, sob forma concreta, que é a ciência. (VAISMAN; ALVES, 2009, p. 9).

Desse modo, ao contrário de certas noções muito familiares no campo da filosofia, é preciso sublinhar que não se trata de um movimento cognitivo por via de uma razão autossustentada, muito ao contrário! Mesmo porque a ontologia, por caráter, propósitos e até mesmo por sua definição clássica, tem por alvo o reconhecimento do por-si das coisas.

\footnotetext{
${ }^{3}$ Trata-se da obra postumamente publicada Para a ontologia do ser social.

${ }^{4}$ Conferir trabalhos do Grupo de Pesquisa Marxologia - Filosofia e Estudos Confluentes - Diretório dos Grupos de Pesquisa do CNPq e também o livro de J. Chasin (2009).
} 
Examinando com cuidado certos aspectos dos escritos marxianos, se constata que já no período de constituição de seu itinerário intelectual, em que Marx se digladiou com as vertentes herdeiras da especulatividade hegeliana, é possível identificar em seus contornos mais decisivos o seu roteiro gnosiológico mesmo que in nuce. Nas suas formulações críticas a Feuerbach, Sitrner, Bruno Bauer, dentre outros, e ao próprio Hegel, Marx

rejeita qualquer tipo de construtivismo especulativo, seja este resultante de alguma tentativa de correção sofisticada - mas, sempre formalizante - dos limites das ciências do entendimento, seja ele - o que vem a ser tão unilateral e equivocado qualquer tipo de edificação, por mais elevada ou tortuosa que seja, de algum cogito transcendental. (VAISMAN, 2006, p. 328).

Evidentemente, tal roteiro se adensa e se apresenta cabalmente constituído em sua obra de maturidade, $O$ capital, mesmo que seu autor não tenha nos legado nenhum tratado autônomo e sistemático acerca da questão, o que já é indicação relevante da sua aversão a projetos gnosiológicos concebidos a priori.

Em outras palavras, ontologia estatutária marxiana não é um sistema abstrato de verdades absolutas ao feitio tradicional, mas um estatuto teórico, cuja fisionomia é traçada por um feixe de lineamentos categoriais enquanto formas de existência do ser social. Ademais, de modo plenamente coerente com o reconhecimento do por-si das coisas, na posição ontológica, o vínculo do entendimento é a objetividade, que se orienta e objetiva pela escavação do objeto real.

Assim sendo, o legado de Marx não pode ser compreendido, como costumeiramente tem se alardeado, como um modelo, seja de qualquer natureza for - inclusive o soi disant modelo dialético,

\footnotetext{
pois seu itinerário filosófico-científico é a apreensão da lógica objetiva dos seres e processos, é a concreção conceitual da regência imanente das existências, e não a logificação da pletora fenomênica pela atribuição a ela de um nexo exterior a ela previamente construído, não importante aqui se este construto seja uma inferência a partir de uma saturação empírica, face à qual, na sequência, se independentiza. (VAISMAN, 2006, p. 240).
}

Não resta dúvida, principalmente depois da publicação da obra tardia de Lukács (2012; 2013) - mas, não só! - que os escritos de Marx acompanham e são o resultado, por continuidade e descontinuidade, do mais consistente posicionamento ontológico que atravessa a história da filosofia. Nesse sentido, podemos afirmar, sem nenhum tom de arrogância ou 
precipitação, que o estatuto e os lineamentos ontológicos da obra de Marx são ponto de chegada de um itinerário clássico, mais de duas vezes milenar.

\section{REFERÊNCIAS}

CHASIN, J. A sucessão na Crise e a Crise na Esquerda. Ensaio 17/18. São Paulo: Editora Ensaio, 1989.

CHASIN, J. Marx: estatuto ontológico e resolução metodológica. São Paulo: Boitempo editorial, 2009.

CHASIN, J. Rota e Prospectiva de Um Projeto Marxista. Ensaios Ad Hominem. São Paulo: Estudos e Edições Ad Hominem, 1999.

LUKÁCS, G. Para uma ontologia do ser social. São Paulo: Boitempo editorial, v. I, 2012 e v. II, 2013.

VAISMAN, E. Marx e a filosofia: elementos para a discussão ainda necessária. Nova Economia, Belo Horizonte, 16(2)327-341, maio agosto de 2006.

VAISMAN, E.; ALVES, A. J. L. Apresentação. In: CHASIN, J. Marx: estatuto ontológico e resolução metodológica. São Paulo: Boitempo editorial, 2009. 